\title{
Transplantation in Atypical Hemolytic Uremic Syndrome
}

\author{
David Kavanagh, M.D., Ph.D., ${ }^{1}$ Anna Richards, M.D., Ph.D., ${ }^{2}$ Tim Goodship, M.D., ${ }^{1}$ \\ and Hannu Jalanko, M.D., Ph.D. ${ }^{3}$
}

Atypical hemolytic uremic syndrome (aHUS) is a disease characterized by overactivation of complement. Recurrence following renal transplantation is determined by a genetic predisposition. Genetic screening of all individuals with aHUS should be performed prior to listing for transplantation. Individuals with isolated mutations in $M C P$ have a low risk of recurrence and may be considered for kidney transplantation alone. In individuals with $C F H$ and $C F I$ mutations, the risk of recurrence following renal transplantation is high. Combined liver/kidney transplantation has been used successfully in individuals with $\mathrm{CFH}$ mutations following the introduction of perioperative plasma exchange; however, such a procedure is not without its risks. Liver/kidney transplantation has yet to be performed on individuals with $C F I$ and $\mathrm{C} 3$ mutations but may be predicted to be successful. In individuals with $\mathrm{CFH}$ autoantibodies, a reduction in titer through plasma exchange and rituximab has been successful. Clinical trials of the complement $\mathrm{C} 5$ inhibitor eculizumab may improve prospects for isolated renal transplantation in individuals with complement protein mutations.

KEYWORDS: Transplantation, hemolytic uremic syndrome, complement, factor $\mathrm{H}$, eculizumab

Hemolytic uremic syndrome (HUS) is a thrombotic microangiopathy that consists of microangiopathic hemolytic anemia, thrombocytopenia, and acute renal failure. HUS is classified as either diarrheal associated (D + HUS) or nondiarrheal (atypical; aHUS). The diarrheal form of the disease is most commonly associated with Shiga toxin-like-producing Escherichia coli. The atypical form of the disease has been shown to be a disorder of complement dysregulation. ${ }^{1}$

Mutations in genes that encode proteins with complement regulatory functions including factor $\mathrm{H}$ $(C F H),{ }^{2-5}$ factor I $(C F I),{ }^{6-8}$ membrane cofactor protein $(M C P, C D 46) \cdot{ }^{9-11}$ Clusterin $^{12}$ and thrombomodulin ${ }^{13}$
(THBD) have been demonstrated to predispose to disease. Autoantibodies against $\mathrm{CFH}$ have also been found in individuals with aHUS. ${ }^{14-16}$ In addition to "loss of function" mutations in genes encoding complement regulatory proteins, activating mutations in the alternative pathway components $\mathrm{C}^{17}$ and factor $\mathrm{B}^{18}(C F B)$ have also been linked to aHUS. Additionally, single nucleotide polymorphisms (SNPs) and haplotypes in the genes encoding regulatory proteins $C F H,{ }^{19,20} M C P,{ }^{20} \mathrm{C} 4 \mathrm{~b}-$ binding protein $(C A B P),{ }^{21}$ and the factor $\mathrm{H}$-related proteins $(C F H R s)^{22}$ have also been demonstrated.

The prognosis in those with D + HUS is good, with few patients rapidly progressing to dialysis-requiring
${ }^{1}$ Institute of Human Genetics, Newcastle University, United Kingdom; ${ }^{2} \mathrm{MRC}$ Centre for Inflammation Research, Queens Medical Research Institute, Edinburgh, United Kingdom; ${ }^{3}$ Hospital for Children and Adolescents, Helsinki University Central Hospital, Helsinki, Finland.

Address for correspondence and reprint requests: David Kavanagh, Institute of Human Genetics, International Centre for Life, Central Parkway, Newcastle upon Tyne, NE1 3BZ United Kingdom (e-mail: davidkavanagh@doctors.org.uk).
Hemolytic Uremic Syndrome; Guest Editors, Reinhard Würzner, M.D., Ph.D., and Lothar-Bernd Zimmerhackl, M.D., Ph.D.

Semin Thromb Hemost 2010;36:653-659. Copyright (C) 2010 by Thieme Medical Publishers, Inc., 333 Seventh Avenue, New York, NY 10001, USA. Tel: +1(212) 584-4662.

DOI: http://dx.doi.org/10.1055/s-0030-1262887.

ISSN 0094-6176. 
renal failure, and with most of those who do, regaining renal function. In contrast, in aHUS, the prognosis is poor with $\sim 50 \%$ of patients requiring dialysis and $25 \%$ dying during the acute phase. ${ }^{23}$

\section{RECURRENCE AFTER RENAL TRANSPLANTATION}

In those patients with D + HUS who do progress to ESRF, renal transplantation is associated with a low recurrence rate, $<1 \% .{ }^{24}$ The 10 -year graft survival is similar to those transplanted for dysplasia/uropathies and significantly better than those transplanted for other renal conditions. ${ }^{25}$

In comparison, the outcome for patients with aHUS is poor, although not uniformly so. The reason for this variation has become clear with the elucidation of the genetic mechanism of disease and the genotypeto-phenotype correlations derived subsequently. ${ }^{26-29}$ There is no evidence that pretransplant bilateral nephrectomy ${ }^{26}$ or avoidance of calcineurin inhibitors is beneficial for preventing post-transplant recurrence of aHUS. $^{27}$

\section{Complement Factor $\mathbf{H}$}

In those with mutations in $\mathrm{CFH}$, disease recurrence occurs following renal transplantation in $\sim 80 \%$ of cases. $^{26-29} \mathrm{CFH}$ functions as the most important fluidphase regulator of the alternative pathway (AP) of complement by acting as a cofactor for CFI-mediated proteolytic inactivation of $\mathrm{C} 3 \mathrm{~b}(\mathrm{CA})$, competing with factor $\mathrm{B}$ for $\mathrm{C} 3 \mathrm{~b}$ binding, and accelerating the decay of the $\mathrm{C} 3$ convertase into its components (decay accelerating activity $[\mathrm{DAA}]$ ). In addition it serves to control complement on host cells by binding cell surface $\mathrm{C} 3 \mathrm{~b}$ and glycosaminoglycans via its $\mathrm{C}$-terminal domains (CCP 19 and20). ${ }^{30}$ It is this region that is mutated in aHUS, resulting in loss of complement regulation on the renal vasculature. ${ }^{31,32}$ Because $\mathrm{CFH}$ is predominantly synthesized in the liver, an isolated kidney allograft will not correct the underlying genetic defect predisposing to aHUS.

Renal transplantation in individuals with $C F H$ mutations has been attempted using prophylactic plasma therapy in several cases. Hirt-Minkowski et $\mathrm{a}^{33}$ report an individual treated with peri- and postoperative plasma infusion who had a successful renal transplant at 1 year. The use of prophylactic plasma exchange $(\mathrm{PE})$ has been described by Olie et $\mathrm{al}^{34}$ in an individual given perioperative $\mathrm{PE}$ and subsequently twice-monthly $\mathrm{PE}$. The graft functioned well; however, aHUS recurrence was seen consequent with cytomegalovirus disease on two occasions with intensification of $\mathrm{PE}$ controlling the recurrence. Other reports of recurrent disease in individuals receiving prophylactic $\mathrm{PE}$ who did not respond to intensification of $\mathrm{PE}$ have been described. ${ }^{35}$ If an isolated renal transplant in an individual with a $\mathrm{CFH}$ mutation must be attempted, then perioperative $\mathrm{PE}$, postoperative $\mathrm{PE}$, and continued prophylactic $\mathrm{PE}$ must be used. Additionally, surveillance must be increased during times of infection with a view to escalation of PE.

\section{Membrane Cofactor Protein}

Transplantation outcome in those with mutations in $M C P$ is much better, with a recurrence rate of only $\sim 20 \%{ }^{26} M C P$ encodes a membrane-bound inhibitor that is highly expressed in the kidney, particularly on endothelium. ${ }^{36}$ Membrane cofactor protein (MCP) is an intrinsic complement regulator, protecting the cell to which it is bound, serving as a cofactor for the proteolytic inactivation of deposited $\mathrm{C} 3 \mathrm{~b}$ and $\mathrm{C} 4 \mathrm{~b}$ by CFI. Around $75 \%$ of $M C P$ mutations described in aHUS lead to reduced surface expression of $\mathrm{MCP}$ on peripheral blood; the remaining mutant proteins have decreased complement regulatory activity. ${ }^{37}$

Because MCP is membrane bound, it would be expected that a renal allograft would correct the complement defect and protect against aHUS. It is surprising, therefore, that recurrence has been reported in two patients.

In the series reported by Frémeaux-Bacchi et $\mathrm{al},{ }^{11}$ patient 6 lost the graft due to recurrence of disease within a few days of transplantation. Functional analysis of the $M C P$ mutation revealed that functional impairment was only seen in the classical pathway (CP), whereas there was evidence of AP activation in the patient's serum. This suggested that the patient may have another mutant complement protein.

In a second patient, Frémeaux-Bacchi et $\mathrm{al}^{38}$ described two episodes of mild disease recurrence responsive to $\mathrm{PE}$, and at 2 years renal function was normal. In this individual, they demonstrated patchy endothelial microchimerism in the graft. This is a mechanism whereby some donor graft endothelial cells are replaced by recipient cells. In this case it was hypothesized that this transfer of recipient mutant MCP-bearing endothelial cells transferred the risk of aHUS to the renal allograft.

Despite these two cases, the overall risk of disease recurrence in individuals with isolated $M C P$ mutations is low, although preoperative counseling should highlight that it is possible.

\section{Complement Factor I}

Factor $\mathrm{I}$ is a serine protease that regulates complement by cleaving $\mathrm{C} 3 \mathrm{~b}$ and $\mathrm{C} 4 \mathrm{~b}$ in the presence of cofactors (CA), such as $\mathrm{CFH}$ and MCP. Approximately $50 \%$ of the CFI mutants associated with aHUS result in low serum levels of complement factor I, with functional 
analysis of secreted mutants revealing loss of $\mathrm{CP}$ and AP cofactor activity. ${ }^{39} \mathrm{CFI}$ is predominantly synthesized in the liver, and as would be predicted from a circulating regulator, the recurrence rate following isolated renal transplantation is high $(\sim 90 \%) .{ }^{26-29}$ In those individuals with disease recurrence, all lost the graft within the first year. ${ }^{26}$

\section{Activating Mutations in Complement Components (CFB and C3)}

More recently, mutations in genes ( $C F B$ and $C 3$ ) encoding the serum complement activating factors $\mathrm{CFB}$ and $\mathrm{C} 3$ have been described in aHUS. Activation of the $\mathrm{CP}$, $\mathrm{AP}$, and lectin pathways results in cleavage of $\mathrm{C} 3$ to generate $\mathrm{C} 3 \mathrm{~b}$ and the anaphylatoxin $\mathrm{C} 3 \mathrm{a}$. Factor $\mathrm{B}$ interacts with $\mathrm{C} 3 \mathrm{~b}$ and following cleavage by factor $\mathrm{D}$ forms the AP convertase $(\mathrm{C} 3 \mathrm{bBb})$. This set of reactions represents an amplification loop. ${ }^{36}$

Mutations in $C F B$ have been demonstrated to enhance the formation of the $\mathrm{C} 3 \mathrm{bBb}$ convertase or increase resistance to inactivation by regulators. ${ }^{18}$ There is only one reported renal transplant in an individual with a $C F B$ mutation, and in this case there was disease recurrence. ${ }^{18}$

Both gain-of-function and loss-of-function mutations have been reported in $\mathrm{C} 3 .{ }^{17}$ Five mutations had impaired binding to complement regulators with a consequent reduction in CA. Two mutations in $C 3$ were also shown to result in decreased secretion of $\mathrm{C} 3$, although the mechanism through which $\mathrm{C} 3$ haploinsufficiency fits into the current complement overactivation model of aHUS remains to be determined. In the six aHUS patients with $C 3$ mutations who were transplanted, three had recurrent disease. ${ }^{17}$

\section{Thrombomodulin Mutations}

Mutations in THBD have recently been demonstrated in aHUS. ${ }^{13}$ THBD is a transmembrane proteoglycan located on the vascular endothelium. It accelerates thrombin-mediated activation of protein $\mathrm{C}$ and enhances thrombin-mediated activation of thrombin activatable fibrinolysis inhibitor (TAFI), which in turn inhibits fibrinolysis and inactivates the anaphylatoxins $\mathrm{C} 3 \mathrm{a}$ and C5a. THBD also suppresses leukocyte trafficking. Additionally, THBD has recently been shown to enhance AP cofactor activity. Besides the transmembrane form, THBD also exists in a soluble form in the plasma, generated by proteolytic cleavage of the membranebound form of the protein, ${ }^{40}$ although the physiological role of the soluble form is unclear. Functional analysis of the mutations described in aHUS demonstrated a decrease in CA and impaired TAFIa generation. Delvaeye et $\mathrm{al}^{13}$ reported one individual with a mutation with recurrent disease following transplantation. Analysis of further large panels of aHUS patients will be required to refine the clinical phenotype following transplantation.

\section{FACTOR H AUTOANTIBODIES}

Autoantibodies to $\mathrm{CFH}$ were first reported to be associated with aHUS in 2005 by Dragon-Durey et al. ${ }^{16}$ This observation has been confirmed in three independent cohorts of aHUS patients at a frequency of $\sim 10 \%{ }^{14,16,41}$ Most auto-antibodies to $\mathrm{CFH}$ bind to the C-terminal end of $\mathrm{CFH}^{14,41}$ Moreover, it has been demonstrated that $\mathrm{CFH}$ autoantibodies impair the binding of $\mathrm{CFH}$ to $\mathrm{C} 3 \mathrm{~b}$ and are associated with enhanced hemolysis of sheep erythrocytes in patient plasma. ${ }^{16,17,41}$ These antibodies have been shown to block the C-terminal recognition domain of $\mathrm{CFH}$ (CCP 19 and 20), an area where it is known that $C F H$ mutations associated with aHUS cluster.

Factor $\mathrm{H}$ autoantibodies have been associated with recurrent disease following renal transplantation. Le Quintrec et $\mathrm{al}^{42}$ reported an individual in which rapid loss of an allograft due to aHUS recurrence was associated with anti-CFH autoantibodies prior to transplantation. In a subsequent renal transplant, $\mathrm{PE}$ was instigated immediately postoperatively and maintained six times weekly to maintain a low titer of CFH autoantibodies, and at 36 months renal function was normal with no recurrence of disease. Kwon et $\mathrm{al}^{43}$ also reported an individual with $\mathrm{CFH}$ autoantibodies in which early detection of anti-CFH autoantibodies allowed their preemptive removal using a regime including the antiCD20 monoclonal antibody, rituximab, PE, and prednisolone and azathioprine. This, in combination with pre- and postoperative PE continued for 4 weeks, resulted in a successful transplant at 2 years. A recent report by Moore et $\mathrm{al}^{14}$ described three individuals with factor $\mathrm{H}$ autoantibodies who had been previously transplanted and had only been found to have autoantibodies through retrospective analysis of historical serum samples. These patients had no recurrence of disease, with follow-up ranging from 2 to 6 years in the absence of specific therapy aimed at reducing $\mathrm{CFH}$ autoantibody titer.

A suggested approach, in light of our current understanding of pathogenesis, is to monitor $\mathrm{CFH}$ autoantibody titer and administer rituximab to those with persistently elevated titers in conjunction with $\mathrm{PE}$ perioperatively.

\section{LIVING RELATED TRANSPLANTATION}

Live related renal transplantation should not currently be attempted in aHUS. As we have discussed, graft loss due to recurrent disease is common in those individuals with mutations in CFH, CFI, CFB, and C3. Additionally, in four reported cases, the donors themselves have gone on 
to develop de novo HUS within a year of donation. ${ }^{44-46}$ It has been suggested that the hyperfiltration induced in the remaining kidney following donation triggered aHUS in the genetically susceptible donor. In at least one of these families, a mutation in $C F H$ was subsequently described. ${ }^{44,47}$

If live donation is considered, it is essential that the donor and recipient undergo genotyping to identify previously unsuspected carriers, given the high reported rates of incomplete penetrance for mutations. One explanation for the $\sim 50 \%$ penetrance is that other genetic factors act as modifiers of disease penetrance. In addition to mutations, several SNPs and haplotypes in complement genes have been associated with disease. Pedigrees have been reported in which co-segregation of three independent genetic risk factors was required for disease to manifest. Thus only when an unfavorable collection of complement genes is present will aHUS develop, and even then only following a triggering event. ${ }^{48}$ Given that a related donor will carry many of the same susceptibility factors, many of which have still to be determined, screening will not completely eliminate the risk for the donor.

\section{LIVER/KIDNEY TRANSPLANTATION}

Because CFH and CFI are predominantly synthesized in the liver, combined liver/kidney transplantation is a potential treatment. Three initial reports describing this procedure in individuals with $C F H$ mutations were not promising.

In 2002 Remuzzi et $\mathrm{al}^{49}$ reported the first combined liver/kidney transplant in a child with a $C F H$ mutation who was failing on dialysis. The liver failed due to hyperacute rejection, and the child developed hepatic encephalopathy and progressed to coma. He underwent a second liver transplant with normalization of liver function; however, there was only partial recovery of his neurological abnormality, which resulted in his death 3 years later. Despite this poor outcome, there was no recurrence of aHUS, supporting a theoretical benefit of this approach.

In the second combined liver/kidney transplant, the child died from primary nonfunction of the liver with autopsy demonstrating widespread microvascular thrombosis with evidence of complement activation. ${ }^{50}$ Because activation of the complement cascade is an unavoidable consequence of organ transplantation, it was suggested that unless there was adequate complement regulation at the time of organ transplantation, the ensuing complement activation would result in graft failure.

Additionally, a child with preserved renal function but recurrent episodes of hemolysis and thrombocytopenia underwent an auxiliary liver transplant from his father but died 10 months after transplant from lymphoproliferative disorder and infection with some evidence of HUS. ${ }^{51}$

To correct the underlying complement regulatory defect prior to combined liver/kidney transplantation, in a 5-year-old child with aHUS and a compound $C F H$ mutation, Saland et $\mathrm{al}^{52}$ performed $\mathrm{PE}$ perioperatively and gave plasma infusion intraoperatively. Enoxaparin and aspirin were also given postoperatively. This resulted in excellent graft function at 4 years with no recurrence of aHUS during this time. A second child with a $C F H$ mutation successfully underwent a combined split liver/ kidney transplant at the same center. ${ }^{53}$ Using a rather similar protocol, successful combined transplants were performed on three patients $(2.5,16$, and 22 years of age) with a heterozygous R1215Q mutation in $C F H^{54}$ (and unpublished results). No disease recurrence occurred in these patients, and both liver and kidney functions are excellent 2 to 3.5 years after the operation. Post-transplantation lymphoma was successfully treated in one, but otherwise the postoperative course has been quite uneventful in all three cases. Altogether, we are aware of 11 recent liver/kidney and one liver transplantation due to CFH mutations as well as one liver/kidney transplantation due to a $C F B$ mutation, with an overall patient survival of $70 \%$. Based on this limited experience, treatment guidelines for the use of liver/kidney transplantation in aHUS were recently proposed by a consensus conference. ${ }^{55}$ To minimize complement activation during the operation, extensive PE (at least 1.5 plasma volumes) preoperatively is recommended. Also, miniheparin and aspirin soon after the operation are suggested for thrombosis prophylaxis. It is clear that even in experienced centers, combined transplantation is associated with surgical and medical risks, and the treatment modality must be chosen on an individual basis. However, in an aHUS patient with terminal renal failure, the use of combined transplantation instead of solitary renal transplantation is beneficial in two ways: the recurrence of renal or neurological problems after the combined operation is very unlikely, and the outcome of the kidney graft is often excellent due to the protective effect of the liver graft (fewer rejections).

Analogously, in those with activating mutations in C3, a combined liver/kidney transplant has been suggested as potential treatment for disease. This is complicated by substantial extrahepatic generation of C3 from the recipient endothelium. Whether this extrahepatic generation of these mutated proteins is sufficient to cause aHUS in an allograft is unclear.

\section{ECULIZUMAB}

Eculizumab is a monoclonal antibody directed against the complement protein $\mathrm{C} 5$. It prevents activation of the terminal complement cascade and the generation of the effector molecules $\mathrm{C} 5 \mathrm{a}$ and $\mathrm{C} 5 \mathrm{~b}-9$. This complement 
Table 1 Genotype-to-Phenotype Correlation in Atypical Hemolytic Uremic Syndrome

\begin{tabular}{|c|c|c|c|c|}
\hline Mutation & Complement Function & Distribution & $\begin{array}{l}\text { Frequency in } \\
\text { aHUS }(\%)\end{array}$ & $\begin{array}{l}\text { Recurrence Rate } \\
\text { after RTx (\%) }\end{array}$ \\
\hline $\mathrm{CFH}$ & Regulator CA, DAA (AP) & Serum & $15-30$ & $\sim 80$ \\
\hline CFI & Regulator CA (protease) & Serum & $5-14$ & $\sim 90$ \\
\hline$M C P$ & Regulator CA (AP/CP) & Membrane & $10-15$ & $\sim 20$ \\
\hline C3 & Activating component & Serum & $5-10$ & $\sim 50$ \\
\hline CFB & Activating component & Serum & $0-3$ & $100^{*}$ \\
\hline THBD & CA Inactivation of C3a and C5a & Serum/Membrane & $\sim 5$ & $100 *$ \\
\hline
\end{tabular}

*Only one individual transplanted with a mutation.

aHUS, atypical hemolytic uremic syndrome; RTx, renal transplant; $\mathrm{CFH}$, factor $\mathrm{H}$; CA, cofactor activity; DAA, decay-accelerating activity; AP alternative pathway; CFI, factor I; MCP, membrane cofactor protein; CP, classical pathway; CFB, factor-B; THBD, thrombomodulin.

inhibitor has recently been reported to salvage a transplanted kidney in an individual with a $C F H$ mutation in whom PE had been unable to stop recurrent aHUS. ${ }^{56}$ Chatelet et al have also reported an individual with a $C 3$ mutation who had received a renal transplant but was dependent on PE to prevent aHUS recurrence. ${ }^{57}$ Longterm treatment with eculizumab in this individual kept the patient in remission. Although treatment with this complement inhibitor may supersede current transplantation protocols in aHUS, systematic trials of eculizumab are required before its use can be universally adopted and recommended for renal transplantation in aHUS.

\section{SUMMARY AND CONCLUSION}

Atypical HUS is a disease of complement overactivation, and recurrence following transplantation is determined by a genetic predisposition (Table 1). Renal transplantation is associated with an activation of complement both at the time of the operation and in the context of acute rejection/infection. Isolated renal transplantation in those with $C F H$ and $C F I$ mutations cannot be recommended currently, due to an unacceptably high rate of primary disease recurrence in the allograft (80 to $100 \%$ in case series). In the limited experience of transplantation in individuals with $C F B, C 3$, and $T H B D$ mutations, the recurrence rate also appears to be high. This risk may be modified in the future by the use of pre/ postoperative $\mathrm{PE}$ or the use of eculizumab, but as yet there are no randomized controlled trials to support these approaches. Combined liver/kidney transplantation has proved successful in treating individuals with CFH mutations following the introduction of perioperative $\mathrm{PE}$, although the risks are not inconsiderable. Liver/kidney transplantation has yet to be performed on individuals with $C F I$ and $C 3$ mutations but may be predicted to be successful. Individuals with isolated mutations in $M C P$ have a low risk of recurrence and can be considered for isolated renal transplantation. In individuals with $\mathrm{CFH}$ autoantibodies, a reduction in titer through $\mathrm{PE}$ and rituximab has been successful.
In conclusion, we would recommend that comprehensive genetic screening and tailored preoperative counseling of all individuals with aHUS must be performed prior to listing for transplantation, ${ }^{58-60}$ and we suggest that live-related transplantation not be undertaken at the present time.

\section{ACKNOWLEDGMENTS}

David Kavanagh is funded by grants from Kidney Research UK, the Academy of Medical Sciences, and the Northern Kidney Research Fund; Anna Richards is funded by a Wellcome Intermediate Fellowship.

\section{REFERENCES}

1. Kavanagh D, Richards A, Atkinson J. Complement regulatory genes and hemolytic uremic syndromes. Annu Rev Med 2008;59:293-309

2. Richards A, Buddles MR, Donne RL, et al. Factor H mutations in hemolytic uremic syndrome cluster in exons 1820, a domain important for host cell recognition. Am J Hum Genet 2001;68(2):485-490

3. Caprioli J, Bettinaglio P, Zipfel PF, et al; Itaslian Registry of Familial and Recurrent HUS/TTP. The molecular basis of familial hemolytic uremic syndrome: mutation analysis of factor $\mathrm{H}$ gene reveals a hot spot in short consensus repeat 20 . J Am Soc Nephrol 2001;12(2):297-307

4. Pérez-Caballero D, González-Rubio C, Gallardo ME, et al. Clustering of missense mutations in the $\mathrm{C}$-terminal region of factor $\mathrm{H}$ in atypical hemolytic uremic syndrome. Am J Hum Genet 2001;68(2):478-484

5. Dragon-Durey MA, Frémeaux-Bacchi V, Loirat C, et al. Heterozygous and homozygous factor $\mathrm{h}$ deficiencies associated with hemolytic uremic syndrome or membranoproliferative glomerulonephritis: report and genetic analysis of 16 cases. J Am Soc Nephrol 2004;15(3):787-795

6. Frémeaux-Bacchi V, Dragon-Durey MA, Blouin J, et al. Complement factor I: a susceptibility gene for atypical haemolytic uraemic syndrome. J Med Genet 2004;41(6): e84

7. Kavanagh D, Kemp EJ, Mayland E, et al. Mutations in complement factor I predispose to development of atypical hemolytic uremic syndrome. J Am Soc Nephrol 2005;16(7): 2150-2155 
8. Caprioli J, Noris M, Brioschi S, et al; International Registry of Recurrent and Familial HUS/TTP. Genetics of HUS: the impact of $\mathrm{MCP}, \mathrm{CFH}$, and IF mutations on clinical presentation, response to treatment, and outcome. Blood 2006;108(4):1267-1279

9. Richards A, Kemp EJ, Liszewski MK, et al. Mutations in human complement regulator, membrane cofactor protein (CD46), predispose to development of familial hemolytic uremic syndrome. Proc Natl Acad Sci U S A 2003; 100(22):12966-12971

10. Noris M, Brioschi S, Caprioli J, et al; International Registry of Recurrent and Familial HUS/TTP. Familial haemolytic uraemic syndrome and an MCP mutation. Lancet 2003; 362(9395):1542-1547

11. Frémeaux-Bacchi V, Moulton EA, Kavanagh D, et al. Genetic and functional analyses of membrane cofactor protein (CD46) mutations in atypical hemolytic uremic syndrome. J Am Soc Nephrol 2006;17(7):2017-2025

12. Ståhl AL, Kristoffersson A, Olin AI, et al. A novel mutation in the complement regulator clusterin in recurrent hemolytic uremic syndrome. Mol Immunol 2009;46(11-12):2236-2243

13. Delvaeye M, Noris M, De Vriese A, et al. Thrombomodulin mutations in atypical hemolytic-uremic syndrome. N Engl J Med 2009;361(4):345-357

14. Moore I, Strain L, Pappworth I, et al. Association of factor $\mathrm{H}$ autoantibodies with deletions of CFHR1, CFHR3, CFHR4, and with mutations in CFH, CFI, CD46, and C3 in patients with atypical hemolytic uremic syndrome. Blood 2010;115(2):379-387

15. Józsi M, Licht C, Strobel S, et al. Factor H autoantibodies in atypical hemolytic uremic syndrome correlate with CFHR1/ CFHR3 deficiency. Blood 2008;111(3):1512-1514

16. Dragon-Durey MA, Loirat C, Cloarec S, et al. Anti-factor $\mathrm{H}$ autoantibodies associated with atypical hemolytic uremic syndrome. J Am Soc Nephrol 2005;16(2):555-563

17. Frémeaux-Bacchi V, Miller EC, Liszewski MK, et al. Mutations in complement $\mathrm{C} 3$ predispose to development of atypical hemolytic uremic syndrome. Blood 2008;112(13): 4948-4952

18. Goicoechea de Jorge E, Harris CL, Esparza-Gordillo J, et al. Gain-of-function mutations in complement factor B are associated with atypical hemolytic uremic syndrome. Proc Natl Acad Sci U S A 2007;104(1):240-245

19. Caprioli J, Castelletti F, Bucchioni S, et al; International Registry of Recurrent and Familial HUS/TTP. Complement factor $\mathrm{H}$ mutations and gene polymorphisms in haemolytic uraemic syndrome: the C-257T, the A2089G and the G2881T polymorphisms are strongly associated with the disease. Hum Mol Genet 2003;12(24):3385-3395

20. Frémeaux-Bacchi V, Kemp EJ, Goodship JA, et al. The development of atypical haemolytic-uraemic syndrome is influenced by susceptibility factors in factor $\mathrm{H}$ and membrane cofactor protein: evidence from two independent cohorts. J Med Genet 2005;42(11):852-856

21. Blom AM, Bergström F, Edey M, et al. A novel nonsynonymous polymorphism (p.Arg240His) in C4b-binding protein is associated with atypical hemolytic uremic syndrome and leads to impaired alternative pathway cofactor activity. J Immunol 2008;180(9):6385-6391

22. Zipfel PF, Edey M, Heinen S, et al. Deletion of complement factor H-related genes CFHR1 and CFHR3 is associated with atypical hemolytic uremic syndrome. PLoS Genet 2007; 3(3):e41
23. Noris M, Remuzzi G. Hemolytic uremic syndrome. J Am Soc Nephrol 2005;16(4):1035-1050

24. Loirat C, Niaudet P. The risk of recurrence of hemolytic uremic syndrome after renal transplantation in children. Pediatr Nephrol 2003;18(11):1095-1101

25. Ferraris JR, Ramirez JA, Ruiz S, et al. Shiga toxin-associated hemolytic uremic syndrome: absence of recurrence after renal transplantation. Pediatr Nephrol 2002;17(10):809-814

26. Loirat C, Frémeaux-Bacchi V. Hemolytic uremic syndrome recurrence after renal transplantation. Pediatr Transplant 2008;12(6):619-629

27. Bresin E, Daina E, Noris M, et al; International Registry of Recurrent and Familial HUS/TTP. Outcome of renal transplantation in patients with non-Shiga toxin-associated hemolytic uremic syndrome: prognostic significance of genetic background. Clin J Am Soc Nephrol 2006;1(1):88-99

28. Sellier-Leclerc AL, Frémeaux-Bacchi V, Dragon-Durey MA, et al; French Society of Pediatric Nephrology. Differential impact of complement mutations on clinical characteristics in atypical hemolytic uremic syndrome. $\mathrm{J} \mathrm{Am} \mathrm{Soc}$ Nephrol 2007;18(8):2392-2400

29. Kavanagh D, Goodship TH. Membrane cofactor protein and factor I: mutations and transplantation. Semin Thromb Hemost 2006;32(2):155-159

30. Schmidt CQ, Herbert AP, Kavanagh D, et al. A new map of glycosaminoglycan and $\mathrm{C} 3 \mathrm{~b}$ binding sites on factor $\mathrm{H}$. J Immunol 2008;181(4):2610-2619

31. Ferreira VP, Herbert AP, Cortés $\mathrm{C}$, et al. The binding of factor $\mathrm{H}$ to a complex of physiological polyanions and $\mathrm{C} 3 \mathrm{~b}$ on cells is impaired in atypical hemolytic uremic syndrome. J Immunol 2009;182(11):7009-7018

32. Lehtinen MJ, Rops AL, Isenman DE, van der Vlag J, Jokiranta TS. Mutations of factor $\mathrm{H}$ impair regulation of surface-bound $\mathrm{C} 3 \mathrm{~b}$ by three mechanisms in atypical hemolytic uremic syndrome. J Biol Chem 2009;284(23):1565015658

33. Hirt-Minkowski P, Schaub S, Mayr M, et al. Haemolytic uraemic syndrome caused by factor $\mathrm{H}$ mutation: is single kidney transplantation under intensive plasmatherapy an option? Nephrol Dial Transplant 2009;24(11):3548-3551

34. Olie KH, Goodship TH, Verlaak R, et al. Posttransplantation cytomegalovirus-induced recurrence of atypical hemolytic uremic syndrome associated with a factor $\mathrm{H}$ mutation: successful treatment with intensive plasma exchanges and ganciclovir. Am J Kidney Dis 2005;45(1):e12-e15

35. Olie KH, Florquin S, Groothoff JW, et al. Atypical relapse of hemolytic uremic syndrome after transplantation. Pediatr Nephrol 2004;19(10):1173-1176

36. Richards A, Kavanagh D, Atkinson JP. Inherited complement regulatory protein deficiency predisposes to human disease in acute injury and chronic inflammatory states: the examples of vascular damage in atypical hemolytic uremic syndrome and debris accumulation in age-related macular degeneration. Adv Immunol 2007;96:141-177

37. Richards A, Kathryn Liszewski M, Kavanagh D, et al. Implications of the initial mutations in membrane cofactor protein (MCP; CD46) leading to atypical hemolytic uremic syndrome. Mol Immunol 2007;44(1-3):111-122

38. Frémeaux-Bacchi V, Arzouk N, Ferlicot S, Charpentier B, Snanoudj R, Dürrbach A. Recurrence of HUS due to CD46/ MCP mutation after renal transplantation: a role for endothelial microchimerism. Am J Transplant 2007;7(8): 2047-2051 
39. Kavanagh D, Richards A, Noris M, et al. Characterization of mutations in complement factor I (CFI) associated with hemolytic uremic syndrome. Mol Immunol 2008;45(1):95105

40. Conway EM, Nowakowski B. Biologically active thrombomodulin is synthesized by adherent synovial fluid cells and is elevated in synovial fluid of patients with rheumatoid arthritis. Blood 1993;81(3):726-733

41. Józsi M, Strobel S, Dahse HM, et al. Anti factor $H$ autoantibodies block C-terminal recognition function of factor $\mathrm{H}$ in hemolytic uremic syndrome. Blood 2007;110(5): 1516-1518

42. Le Quintrec M, Zuber J, Noel LH, et al. Anti-factor H autoantibodies in a fifth renal transplant recipient with atypical hemolytic and uremic syndrome. Am J Transplant 2009;9(5):1223-1229

43. Kwon T, Dragon-Durey MA, Macher MA, et al. Successful pre-transplant management of a patient with anti-factor $\mathrm{H}$ autoantibodies-associated haemolytic uraemic syndrome. Nephrol Dial Transplant 2008;23(6):2088-2090

44. Donne RL, Abbs I, Barany P, et al. Recurrence of hemolytic uremic syndrome after live related renal transplantation associated with subsequent de novo disease in the donor. Am J Kidney Dis 2002;40(6):E22

45. Bergstein J, Michael A Jr, Kellstrand C, Simmons R, Najarian J. Hemolytic-uremic syndrome in adult sisters. Transplantation 1974;17(5):487-490

46. Kaplan BS, Papadimitriou M, Brezin JH, Tomlanovich SJ, Zulkharnain . Renal transplantation in adults with autosomal recessive inheritance of hemolytic uremic syndrome. Am J Kidney Dis 1997;30(6):760-765

47. Heinen S, Sanchez-Corral P, Jackson MS, et al. De novo gene conversion in the RCA gene cluster (1q32) causes mutations in complement factor $\mathrm{H}$ associated with atypical hemolytic uremic syndrome. Hum Mutat 2006;27(3):292293

48. Kavanagh D, Goodship TH, Richards A. Atypical haemolytic uraemic syndrome. Br Med Bull 2006;77-78:5-22

49. Remuzzi G, Ruggenenti P, Codazzi D, et al. Combined kidney and liver transplantation for familial haemolytic uraemic syndrome. Lancet 2002;359(9318):1671-1672
50. Remuzzi G, Ruggenenti P, Colledan M, et al. Hemolytic uremic syndrome: a fatal outcome after kidney and liver transplantation performed to correct factor $\mathrm{H}$ gene mutation. Am J Transplant 2005;5(5):1146-1150

51. Cheong HI, Lee BS, Kang HG, et al. Attempted treatment of factor $\mathrm{H}$ deficiency by liver transplantation. Pediatr Nephrol 2004;19(4):454-458

52. Saland JM, Emre SH, Shneider BL, et al. Favorable longterm outcome after liver-kidney transplant for recurrent hemolytic uremic syndrome associated with a factor $\mathrm{H}$ mutation. Am J Transplant 2006;6(8):1948-1952

53. Saland JM, Shneider BL, Bromberg JS, et al. Successful split liver-kidney transplant for factor $\mathrm{H}$ associated hemolytic uremic syndrome. Clin J Am Soc Nephrol 2009;4(1):201206

54. Jalanko H, Peltonen S, Koskinen A, et al. Successful liverkidney transplantation in two children with aHUS caused by a mutation in complement factor $\mathrm{H}$. Am J Transplant 2008;8(1):216-221

55. Saland JM, Ruggenenti P, Remuzzi G; Consensus Study Group. Liver-kidney transplantation to cure atypical hemolytic uremic syndrome. J Am Soc Nephrol 2009;20(5):940-949

56. Nürnberger J, Philipp T, Witzke $O$, et al. Eculizumab for atypical hemolytic-uremic syndrome. N Engl J Med 2009; 360(5):542-544

57. Chatelet V, Frémeaux-Bacchi V, Lobbedez T, Ficheux M, Hurault de Ligny B. Safety and long-term efficacy of eculizumab in a renal transplant patient with recurrent atypical hemolytic-uremic syndrome. Am J Transplant 2009; 9(11):2644-2645

58. Loirat C, Noris M, Frémeaux-Bacchi V. Complement and the atypical hemolytic uremic syndrome in children. Pediatr Nephrol 2008;23(11):1957-1972

59. Kavanagh D, Richards A, Frémeaux-Bacchi V, et al. Screening for complement system abnormalities in patients with atypical hemolytic uremic syndrome. Clin J Am Soc Nephrol 2007;2(3):591-596

60. Ariceta G, Besbas N, Johnson S, et al; European Paediatric Study Group for HUS. Guideline for the investigation and initial therapy of diarrhea-negative hemolytic uremic syndrome. Pediatr Nephrol 2009;24(4):687-696 